\title{
STRATEGI PENGEMBANGAN WISATA PANTAI BATU GONG DI DESA BATU GONG KECAMATAN LALONGGASUMEETO KABUPATEN KONAWE
}

\author{
Development Analysis of Batu Gong Beachin Batu Gong Village \\ Lalonggasumeeto District Konawe Regency
}

\author{
Jusran Thayeb $^{1}$, Sjamsu Alam Lawelle ${ }^{2}$, dan Rosmawati ${ }^{2}$ \\ 1) Mahasiswa Jurusan/Program Studi Agrobisnis Perikanan FPIK UHO \\ 2) Dosen Jurusan/Program Studi Agrobisnis PerikananFPIK UHO \\ Email : sayajusran1997@gmail.com
}

\begin{abstract}
ABSTRAK
Penelitian ini bertujuan untuk mengetahui strategi pengembangan wisata pantai Batu Gong di Desa Batu Gong Kecamatan Lalonggasumeeto Kabupaten Konawe, yang dilaksanakan pada bulan Oktober sampai November 2019. Pemilihan lokasi penelitian dilakukan secara purposive. Tehnik pengambilan sampel digunakan pada penelitian ini menggunakan dua metode yaitu accidential sampling dan purposive sampling. Analisis data yang digunakan dalam penelitian ini adalahanalisis SWOT yang bertujuan untuk melihat kekuatan, kelemahan, peluang dan ancaman.Hasil analisis bahwa strategi pengembangan pantai Batu Gong adalah (S-O) memanfaatkan lokasi mudah diakses wisatawan serta menambah fasilitas untuk menarik minat masyarakat untuk berkunjung, memanfaatkan lokasi yang membentang luas yang dapat digunakan sebagai lapangan pekerjaan sehingga dapat meningkatkan perekonomian masyarakat setempat, memanfaatkan teknologi media sosial dan media cetak untuk memperkenalkan objek wisata, dan memanfaatkan hubungan baik dengan seluruh stakeholderuntuk meningkatkan penyediaan fasilitas. (S-T) meningkatkan keamanan untuk menghindari terjadinya tindak kriminal pada wisatawan dan emanfaatkan lokasi yang mudah dijangkau, fasilitas yang tersedia sebagai keunggulan objek wisata dari pesaing objek wisata lain. (W-O) meningkatkan hubungan melalui kerja sama yang baik dengan stackholder terkait pengelolaan kebersihan pantai, penataan serta persediaan gazebo dan meningkatkan kegiatan promosi di media sosial dan media cetak untuk memperkenalkan objek wisata. (W-T) meningkatkan kebersihan pantai dan pengontrolan dari pihak berwajib untuk mengurangi resiko tawuran/perkelahian dan tindak kriminal.
\end{abstract}

Kata Kunci : Pengembangan, Wisata, Pantai

\begin{abstract}
This study aims to determine the developing strategy of Batu Gong beach tourism in Batu Gong Village, Lalonggasumeeto District, Konawe Regency, which was carried out from October to November 2019. The selection of research locations was carried out purposively. The sampling technique used in this study used two methods, namely accidential sampling and purposive sampling. The data analysis used in this study is a SWOT analysis which aims to see the strengths, weaknesses, opportunities and threats. The results of the analysis show that the Batu Gong beach development strategy is (SO) utilizing locations that are easily accessible to tourists and adding facilities to attract people to visit, take advantage of the location. which stretches widely that can be used as employment opportunities so as to improve the economy of the local community, utilize social media technology and print media to introduce tourism objects, and take advantage of good relations with all stakeholders to improve the provision of facilities. $(S-T)$ increases security to avoid criminal acts against tourists and takes advantage of the easy-to-reach location, available facilities as a tourist attraction's advantage over other tourist attraction competitors. $(W-O)$ enhances relations through good cooperation with stakeholders related to beach cleanliness management, arrangement and supplies of gazebos and increasing promotional activities on social media and print media to introduce tourist objects. $(W-T)$ improve beach cleanliness and control from the authorities to reduce the risk of brawls / fights and criminal acts.
\end{abstract}

Keywords: Development, Tourism, Beach 


\section{PENDAHULUAN}

Pariwisata sekarang ini menjadi aktivitas ekonomi yang penting memberikan kesempatan kepada pengelola dan stakeholder untuk mendapatkan nilai tambah berupa manfaat finansial hal ini sejalan dengan tujuan dari pengelolaan pariwisata yakni untuk mendorong masyarakat dalam pengembangan dan pengelolaan, memberikan dukungan bisnis bagi industri pariwisata serta untuk meningkatkan status pariwisata dari sub-sektor pembangunan menjadi pembangunan andalan yang mampu meningkatkan perekonomian.

Pengembangan kawasan wisata pantai di daerah Sulawesi Tenggara adalah salah satu bentuk pelestarian serta pemanfaatan potensi wisata dan jasa lingkungan sumberdaya alam khususnya daerah pesisir pantai. Dilain pihak masyarakat dapat merasakan manfaat secara langsung di sektor kepariwisataan melalui terbukanya peluang usaha serta mampu meningkatkan pendapatan masyarakat yang berada disekitar pantai pesisir. Salah satu yang tercakup disini adalah zonasi dan penataan ruang serta penambahan obyek wisata konservasi disekitaran tebing pinggir pantai. Pengelolaan ini bersifat berkelanjutan dan berbasis kemasyarakatan dan diharapkan memberikan keuntungan antara lain: meningkatnya kesejahteraan masyarakat lokal, terbukanya kesempatan kerja, pertumbuhan ekonomi dan pengembangan wilayah.

Untuk mendukung keberhasilan kepariwisataan maka sarana dan prasarana kepariwisataan tersebut harus dibenahi secara berkelanjutan. Kondisi geografis khususnya pesona alam dan budaya Kabupaten Konawe merupakan modal dasar pembangunan pariwisata. Potensi pariwisata yang ada di
Kabupaten Konawe adalah Wisata alam permandian air panas, Pantai Batu Gong, Pantai Toronipa dan Watunggarandu serta Pulau Bokori; wisata Budaya (kesenian) seperti Tarian Lulo, dan lainlain.

Kabupaten Konawe bisa menjadi daerah tujuan wisata yang handal, maka perlu dilakukan kegiatan diantaranya melakukan promosi yang lebih instensif, mempersiapkan kalender wisata Kabupaten Konawe secara integral dan merupakan bagian dari kalender wisata nusantara atau daerah sekitar serta perlunya dikembangkan bentuk kerjasama yang saling menguntungkan dengan pihak swasta khususnya dalam pembenahan tempat-tempat wisata maupun pelaku pariwisata/biro perjalanan dalam upayanya mendatangkan wisatawan (RPJMD Kabupaten Konawe Tahun2008 -2013)

Pantai Batu Gong merupakan pantai yang berada di Desa Batu Gong Kecamatan Lalonggasumeeto Kabupaten Konawe, pantai yang letaknya cukup strategis karena dekat dengan Kota Kendari, membuat Pantai Batu Gong mudah untuk dijangkau oleh kendaraan roda dan roda empat karena akses transportasi lancar.

Pantai Batu Gong adalah salah satu pantai yang berpotensi untuk dikembangkan karena melihat dari aspek tata ruang pantai dan tambahan permandian yang dikhususkan untuk anak-anak usia dibawah umur, garis pantai yang panjang hal ini bisa digunakan sebagian garis pantai tersebut untuk menambahkan tempat olahraga baik tempat lapangan voli serta lapangan bola mini dan tebing yang bisa dijadikan objek konservasi wisata tambahan dengan, menambahan taman-taman dan membangun rumah adat untuk lebih 
menarik wisatawan. Akan tetapi ada beberapa kendala dalam potensi pengembangan pantai tersebut, berdasarkan survei awal dilapangan antara lain :kurangnya kerja sama antara masyarakat dengan pihak pemerintah setempat dalam hal keamanan pengunjung dan kurangnya publikasi tentang wisata pantai tersebut. Selain itu, mengelola area pantai dan pengunjung kurang memperhatikan kebersihan pantai (sampah), Hal inilah yang membuat kurangnya jumlah pengunjung ditiap hari kerja sabtu dan minggu. Berdasarkan latar belakang di atas, peneliti merasa tertarik untuk melakukan penelitian dengan judul: "Analisis Pengembangan Wisata Pantai Batu Gong di Desa Batu Gong Kecamatan Lalonggasumeeto Kabupaten Konawe."

Tujuan dari penelitian ini adalah mengetahui strategi pengembangan wisata pantai Batu Gong di Desa Batu Gong Kecamatan Lalonggasumeeto Kabupaten Konawe.

\section{METODE PENELITIAN}

Penelitian ini dilaksakan pada bulan Oktober sampai November 2019, di Desa Batu Gong Kecamatan Lalonggasumeeto Kabupaten Konawe Provinsi Sulawesi Tenggara. Penentuan lokasi secara sengaja (purposive) dengan pertimbangan bahwa lokasi wisata tersebut merupakan salah satu lokasi yang ada pada Kabupaten Konawe Provinsi Sulawesi Tenggara.

Tehnik pengambilan sampel digunakan pada penelitian ini menggunakan dua metode yaitu accidential sampling dan purposive sampling.Accidential sampling adalah pengambilan sampel yang dilakukan kepada siapa saja yang kebetulan ada (Soeratno dkk., 2008). Siapa saja disini ditujukan kepada wisatawan yang sedang berekreasi di Pantai Batu Gong Kecamatan Lalonggasumeeto Kabupaten Konawe yang berjumlah 6 orang. Menurut Sugiyono, (2012) Purposive Sampling adalah teknik penentuan sampel dengan dan pertimbangan tertentu. Purposive Sampling ditujukan kepada pemerintah yang berjumlah 3 orang dan pelaku yang berjumlah 4 orang. Sehingga total keseluruhan sampel yang digunakan yakni 14 orang.

Pengumpulan data diperoleh data primer dan data sekunder. Data primer yakni data yang diperoleh langsung dari pemerintah, masyarakat lokal dan pengunjung (konsumen) yang didukung menggunakan kuesioner yang diperoleh dengan cara wawancara, observasi, dan dokumentasi. Data sekunder merupakan data yang diperoleh dari pustaka dan lembaga yang terkait dengan penelitian ini.

Analisis data yang digunakan adalah analisis SWOT, bertujuan untuk melihat kekuatan (Strength), kelemahan (Weakness), peluang (Opportunity) dan ancaman (Threat).

\section{HASIL DAN PEMBAHASAN}

Hasil pengukuran IFAS (Internal Factors Analyis Strategy) dan EFAS (Eksternal Factors Analyis Strategy)atas jawaban responden terhadap faktor lingkungan internal wisata Pantai Batu Gong, didapat 5 kekuatan, 4 kelemahan,5 peluang dan 4 ancaman dari bobot nilai terprioritas yang terlihat pada Tabel 1 berikut. 
Tabel 1. Faktor Internal dan Eksternal Pengembangan Wisata Pantai Batu Gong

\begin{tabular}{|c|c|c|c|c|}
\hline Indikator & Faktor Strategi Internal & Bobot & Rating & $\begin{array}{l}\text { Bobot } x \\
\text { Rating }\end{array}$ \\
\hline \multirow{6}{*}{$\begin{array}{l}\text { Kekuatan } \\
\text { (Strength) }\end{array}$} & $\begin{array}{l}\text { 1. Lokasi yang mudah diakses } \\
\text { wisatawan dan dekat Kota } \\
\text { Kendari }\end{array}$ & 0,21 & 3 & 0,69 \\
\hline & $\begin{array}{l}\text { 2. Memiliki fasilitas gazebo, air } \\
\text { bersih, mushola, kantin, kapal } \\
\text { pincara, dan tempat sampah }\end{array}$ & 0,20 & 3 & 0,66 \\
\hline & $\begin{array}{l}\text { 3. Memiliki lokasi yang } \\
\text { membentang luas }\end{array}$ & 0,20 & 3 & 0,66 \\
\hline & $\begin{array}{l}\text { 4. Objek wisata yang terkenal } \\
\text { sudah cukup lama }\end{array}$ & 0,20 & 3 & 0,66 \\
\hline & $\begin{array}{l}\text { 5. Memiliki pemandangan sunrise } \\
\text { yang indah }\end{array}$ & 0,19 & 3 & 0,66 \\
\hline & Jumlah & & & 3,26 \\
\hline \multirow{5}{*}{$\begin{array}{l}\text { Kelemahan } \\
\text { (Weakness) }\end{array}$} & 1. Pantai kotor & 0,21 & 2 & 0,51 \\
\hline & 2. Kurangnya kegiatan promosi & 0,27 & 3 & 0,78 \\
\hline & $\begin{array}{l}\text { 3. Penataan gazebo yang tidak } \\
\text { teratur }\end{array}$ & 0,29 & 3 & 0,94 \\
\hline & 4. Pasir berwarna keruh & 0,23 & 3 & 0,57 \\
\hline & Jumlah & & & 2,79 \\
\hline \multirow{6}{*}{$\begin{array}{c}\text { Peluang } \\
\text { (Opportunities) }\end{array}$} & $\begin{array}{l}\text { 1. Adanya lapangan pekerjaan } \\
\text { bagi masyarakat setempat }\end{array}$ & 0,19 & 3 & 0,53 \\
\hline & $\begin{array}{l}\text { 2. Meningkatkan perekonomian } \\
\text { masyarakat setempat }\end{array}$ & 0,20 & 3 & 0,59 \\
\hline & $\begin{array}{l}\text { 3. Hubungan kerja sama yang baik } \\
\text { dengan stakeholder dalam } \\
\text { lingkup pariwisata }\end{array}$ & 0,20 & 3 & 0,59 \\
\hline & $\begin{array}{l}\text { 4. Adanya teknologi informasi } \\
\text { media sosial dan media cetak } \\
\text { untuk kegiatan promosi wisata }\end{array}$ & 0,22 & 3 & 0,71 \\
\hline & $\begin{array}{l}\text { 5. Adanya minat masyarakat untuk } \\
\text { mengunjungi pantai batu gong }\end{array}$ & 0,19 & 3 & 0,53 \\
\hline & Jumlah & & & 2,94 \\
\hline \multirow{5}{*}{$\begin{array}{l}\text { Ancaman } \\
\text { (Treats) }\end{array}$} & $\begin{array}{l}\text { 1. Adanya persaingan objek wisata } \\
\text { lain }\end{array}$ & 0,23 & 2 & 0,44 \\
\hline & 2. Adanya tindak kriminal & 0,26 & 2 & 0,58 \\
\hline & $\begin{array}{l}\text { 3. Keamanan kurang terjamin } \\
\text { 4. Sering terjadi }\end{array}$ & 0,29 & 2 & 0,69 \\
\hline & $\begin{array}{l}\text { tawuran/perkelahian pemuda } \\
\text { setempat }\end{array}$ & 0,23 & 2 & 0,44 \\
\hline & Jumlah & & & 2,15 \\
\hline
\end{tabular}

Sumber :Data Primer Setelah Diolah, 2020

\section{Matriks SWOT}

Matriks SWOT akan menggambarkan dengan jelas bagaimana Analisis pengembangan wisata Pantai Batu Gong berdasarkan kekuatan, kelemahan yang dimiliki dalam rangka merespon peluang dan menghadapi ancaman yang ada. Matriks ini akan menghasilkan empat jenis strategi utama yaitu: strategi S-O, W-O, S-T dan W-T yang sebagaimana tersaji pada Tabel 2 sebagai berikut: 
Tabel 2. Matriks SWOT Pengembangan Wisata Pantai Batu Gong

\begin{tabular}{|c|c|c|}
\hline Eksternal & $\begin{array}{l}\text { Strength (S) } \\
\text { 1. Lokasi yang mudah diakses } \\
\text { wisatawan dan dekat Kota } \\
\text { Kendari } \\
\text { 2. Memiliki fasilitas gazebo, air } \\
\text { bersih, mushola, kantin, kapal } \\
\text { pincara, dan tempat sampah } \\
\text { 3. Memiliki lokasi yang } \\
\text { membentang luas } \\
\text { 4. Objek wisata yang terkenal } \\
\text { sudah cukup lama } \\
\text { 5. Memiliki pemandangan sunrise } \\
\text { yang indah }\end{array}$ & $\begin{array}{l}\text { Weakness }(\mathbf{W}) \\
\text { 1. Pantai kotor } \\
\text { 2. Kurangnya kegiatan } \\
\text { promosi } \\
\text { 3. Penataan gazebo } \\
\text { yang tidak teratur } \\
\text { 4. Pasir pantai } \\
\text { berwarna keruh }\end{array}$ \\
\hline $\begin{array}{l}\text { Opportunities }(\mathbf{O}) \\
\text { 1. Adanya lapangan } \\
\text { pekerjaan bagi } \\
\text { masyarakat setempat } \\
\text { 2. Meningkatkan } \\
\text { perekonomian } \\
\text { masyarakat setempat } \\
\text { 3. Hubungan kerja sama } \\
\text { yang baik dengan } \\
\text { stakeholder dalam } \\
\text { lingkup pariwisata } \\
\text { 4. Adanya teknologi } \\
\text { informasi media sosial } \\
\text { dan media cetak untuk } \\
\text { kegiatan promosi } \\
\text { wisata } \\
\text { 5. Adanya minat } \\
\text { masyarakat untuk } \\
\text { mengunjungi pantai } \\
\text { batu gong }\end{array}$ & $\begin{array}{l}\text { Strategi S-O } \\
\text { 1. Memanfaatkan lokasi mudah } \\
\text { dijangkau wisatawan serta } \\
\text { menambah fasilitas untuk menarik } \\
\text { minat masyarakat untuk } \\
\text { berkunjung (S1,S2,O5) } \\
\text { 2. } \text { Memanfaatkan lokasi yang } \\
\text { membentang luas yang dapat } \\
\text { digunakan sebagai lapangan } \\
\text { pekerjaan sehingga dapat } \\
\text { meningkatkan perekonomian } \\
\text { masyarakat setempat (S3, O1,O2) } \\
\text { 3. } \text { Memanfaatkan teknologi media } \\
\text { sosial dan media cetak untuk } \\
\text { memperkenalkan objek wisata } \\
\text { (S1,S2,S3,O4) } \\
\text { 4. } \text { Meningkatkan hubungan baik } \\
\text { dengan seluruh stakeholderuntuk } \\
\text { meningkatkan penyediaan fasilitas } \\
\text { (S2,S3,O3) }\end{array}$ & $\begin{array}{l}\text { Strategi W-O } \\
\text { 1. Meningkatkan } \\
\text { hubungan dan kerja } \\
\text { sama yang banyak } \\
\text { dengan } \\
\text { stakeholderterkait } \\
\text { dengan pengelolaan } \\
\text { kebersihan pantai, } \\
\text { penataan dan } \\
\text { persediaan gazebo } \\
\text { sehingga wisatawan } \\
\text { tertarik untuk } \\
\text { berkunjung } \\
\text { (W1,W3,O3,O5) } \\
\text { 2. Meningkatkan } \\
\text { kegiatan promosi di } \\
\text { media sosial dan } \\
\text { media cetak untuk } \\
\text { memperkenalkan } \\
\text { objek wisata pantai } \\
\text { batu gong (W2,O4) }\end{array}$ \\
\hline \begin{tabular}{l}
\multicolumn{1}{c}{ Treats (T) } \\
1. Adanya persaingan \\
objek wisata lain \\
2. Adanya tindak \\
kriminal \\
3. Keamanan kurang \\
terjamin \\
4. Sering terjadi tawuran/ \\
perkelahian pemuda \\
setempat
\end{tabular} & $\begin{array}{l}\text { Strategi S-T } \\
\text { 1. Meningkatkan keamanan untuk } \\
\text { menghindari terjadinya tindak } \\
\text { kriminal pada wisatawan } \\
\text { (S3,T2,T3,T4) } \\
\text { 2. Memanfaatkan lokasi yang } \\
\text { mudah dijangkau, fasilitas yang } \\
\text { tersedia sebagai keunggulan } \\
\text { objek wisata dari pesaing objek } \\
\text { wisata lain (S1,S2,T1) }\end{array}$ & $\begin{array}{l}\text { Strategi W-T } \\
\text { 1. Meningkatkan } \\
\text { kebersihan pantai } \\
\text { dan pengontrolan } \\
\text { dari pihak berwajib } \\
\text { untuk mengurangi } \\
\text { resiko tawuran/ } \\
\text { perkelahian dan } \\
\text { tindak kriminal } \\
\text { (W4,T2,T3,T4) }\end{array}$ \\
\hline
\end{tabular}

Sumber : Data Primer Setelah Diolah, 2020

\section{a. Strategi S-O}

- Memanfaatkan Lokasi Mudah Diakses Wisatawan Serta Menambah
Fasilitas Untuk Menarik Minat Masyarakat Berkunjung 
Berdasarkan hasil perengkingan prioritas utama yang digunakan untuk strategi pengembangan wisata Pantai Batu Gongyakni memanfaatkan lokasi mudah diakses wisatawan serta menambah fasilitas untuk menarik minat masyarakat untuk berkunjung dinyatakan sebagai prioritas ke-6. Lokasi Pantai Batu Gong dapat ditempuh menggunakan roda dua maupun roda empat dengan memerlukan waktu \pm 30 menit dengan jarak perjalanan $14 \mathrm{~km}$ dari Kota Kendari, hal ini tentunya memberikan kemudahan masayarakat setempat untuk menyediakan jasa transportasi untuk mempermudah wisatawan berkunjung. Selain itu, menambah fasilitas-fasilitas yang tersedia juga menjadi poin penting untuk menarik minat masyarakat berkunjung, tidak hanya wisata kuliner RM. Ikan Bakar yang berjumlah 5 unit wisata kuliner lain perlu ditingkatkan seperti kedai kopi dan kedai minuman penyegar seperti es kelapa dan es buah, penginapan dan kantor pusat informasi. Hal ini sejalan dengan hasil penelitian Hidayat (2016) bahwa dengan menambah dan meningkatkan fasilitasfasilitas wisata, wisatawan akan merasa nyaman.

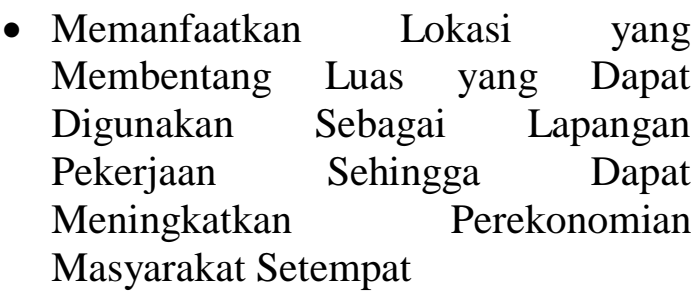

Berdasarkan hasil perengkingan prioritas utama yang digunakan untuk strategi pengembangan wisata Pantai Batu Gongyakni memanfaatkan lokasi yang membentang luas yang dapat digunakan sebagai lapangan pekerjaan sehingga dapat meningkatkan perekonomian masyarakat setempat dinyatakan sebagai prioritas ke-5. Lokasi yang membentang luas dapat menjadi potensi oleh masyarakat lokal untuk berusaha seperti menjual berbagai hasil bumi, wisata kuliner, pernak pernik hasil kreasi, menyediakan jasa penyewaan peralaratan snorkling, diving (bawah air) peralatan rekreasi pantai (tikar, pelampung dan bean bag) dan pemandu (tour guide). Hal ini diharapkan dapat meningkatkan lapangan pekerjaan bagi masyarakat setempat sehingga usaha yang dijalankan diharpkan dapat meningkatkan kesejahteraan. Hal ini sejalan dengan hasil penelitian Razak $d k k$, (2017) bahwa adanya wisata kuliner menjadi pelengkap wisata pantai, prasarana jalan yang memadai, dan lokasi yang strategis sehingga membuka kesempatan berusaha bagi masyarakat lokal.

- Memanfaatkan Teknologi Media Sosial dan Media Cetak untuk Memperkenalkan Objek Wisata

Berdasarkan hasil perengkingan prioritas utama yang digunakan untuk strategi pengembangan wisata Pantai Batu Gongyakni memanfaatkan teknologi media sosial dan media cetak untuk memperkenalkan objek wisata yang dinyatakan sebagai prioritas ke-8. Kurangnya promosi merupakan salahsatu penyebab kurangnya wisatawan yang berkunjung di Pantai Batu Gong. Melalui pemanfaatan media sosial seperti facebook, instagram dan twitter serta media cetak seperti brosur dapat menjadi solusi yang tepat untuk memperkenalkan Pantai Batu Gong kepada masyarakat sehingga pengunjung yang berwisata di Pantai Batu Gong dapat terus meningkat. Hal ini sejalan dengan pendapat Nafiah (2010) dan Hepi et al., (2015) bahwa promosi obyek pariwisata kepada masyarakat digunakan mengetahui bahwa ada obyek pariwisata yang baik untuk di kunjungi serta dapat 
meningkatkan jumlah arus kunjungan wisatawan.

- Memanfaatkan Komunikasi Baik dengan Seluruh Stackholder untuk Meningkatkan Penyediaan Fasilitas

Berdasarkan hasil perengkingan prioritas utama yang digunakan untuk strategi pengembangan wisata Pantai Batu Gongyakni meningkatkan hubungan baik dengan seluruh stackholder untuk meningkatkan penyediaan fasilitas yang dinyatakan sebagai prioritas ke-1 (utama). Hubungan yang baik kepada seluruh lapisan masyarakat (stackholder) khususya pemerintah dan masyarakat setempat dapat meningkatkan kerja sama yang baik sehingga fasilitas yang tersedia dapat ditingkatkan. Melalui bantuan pemerintah daerah ataupun pemerintah setempat jumlah fasilitas berupa sarana dan prasarana seperti penginapan, kantor pusat informasi dan peralatan wisata dapat ditingkatkan sehingga dapat meningkatkan kenyamanan pengunjung yang berwisata yang diharapkan berdampak pada jumlah araus kunjungan wisatawan. Hal ini sejalan dengan penelitian Maharani $d k k$, (2015) bahwa sarana dan prasarana merupakan salah satu faktor penunjang kenyamanan pengunjung di kawasan wisata. Selain itu menurut Ayob $d k k$, (2009) bahwa untuk mendapatkan tingkat kepuasan pengunjung, peningkatan sarana dan prasarana harus berdasarkan aspek konservasi, keruangan, keselamatan, kenyamanan serta disesuaikan dengan kegiatan ekowisata yang ditawarkan.

\section{b. Strategi S-T}

- Meningkatkan Keamanan untuk Menghindari Terjadinya Tindak Kriminal pada Wisatawan
Berdasarkan hasil perengkingan prioritas utama yang digunakan untuk strategi pengembangan wisata Pantai Batu Gongyakni meningkatkan keamanan untuk menghindari terjadinya tindak kriminal pada wisatawan yang dinyatakan sebagai prioritas ke-2. Pengamanan objek wisata adalah keamanan tindakan kriminal dari penjahat yang sering terjadi pada malam hari dan kecelakaan lalu lintas di sepanjang jalan Pantai Panjang yang berujung dengan maut. Untuk masalah pengamanan kawasan wisata, yang perlu dilakukan adalah adalah membuat posko-posko keamaan dan menyedikan life guard, sehingga dapat memperhatikan pengunjung yang berada pada kawasan yang rawan. Pengamanan lainnya adalah pemasangan ramburambu/larangan tempat berbahaya untuk tempat mandi para pengunjung. Antisipasi ini harus segera dilakukan, mengingat kecelakaan sering terjadi pada waktu tahun baru/liburan sekolah dengan pengunjung yang sangat banyak terutama dari luar kota. Hal ini dapat diartikan bahwa kemanan merupakan hal yang penting untuk mengurangi resiko terjadinya tindak kriminal dan ancaman lainnya. Hal ini sesuai dengan pendapat Pratama dan Sakti, (2016) pihak yang berwajib atau keamanan sangat dibutuhkan sehingga dapat menciptakan rasa aman dan nyaman bagi wisatawan yang berkunjung di suatu obyek wisata.

- Memanfaatkan Lokasi yang Mudah Dijangkau, Fasilitas yang Tersedia Sebagai Keunggulan Objek Wisata dari Pesaing Objek Wisata Lain

Berdasarkan hasil perengkingan prioritas utama yang digunakan untuk strategi pengembangan wisata Pantai Batu Gongyakni memanfaatkan lokasi yang mudah dijangkau, fasilitas yang tersedia 
sebagai keunggulan objek wisata dari pesaing objek wisata lain yang dinyatakan sebagai prioritas ke-4. Lokasi Pantai Batu Gong dapat ditempuh menggunakan roda dua maupun roda empat dengan memerlukan waktu \pm 30 menit dengan jarak perjalanan $14 \mathrm{~km}$ dari Kota Kendari, hal ini tentunya memberikan kemudahan masyarakat dari daerah setempat maupun dari luar. Kondisi tersebut dapat dimanfaatkan oleh masyarakat setempat dengan menyediakan fasilitas berupa jasa transportasi sehingga memudahakan pengunjung untuk berwisata di Pantai Batu Gong.

\section{c. Strategi W-O}

- Meningkatkan Hubungan Melalui Kerja Sama Yang Baik dengan Stackholder Terkait Pengelolaan Kebersihan Pantai, Penataan dan Persediaan Gazebo Sehingga Wisatawan Tertarik Untuk Berkunjung

Berdasarkan hasil perengkingan prioritas utama yang digunakan untuk strategi pengembangan wisata Pantai Batu Gongyakni pengelolaan kebersihan pantai, penataan dan persediaan gazebo sehingga wisatawan tertarik untuk berkunjung yang dinyatakan sebagai prioritas ke-1 (utama). Kebersihan merupakan faktor kenyamanan dari obyek wisata pantai, di obyek wisata pantai khususnya pantai Batu Gong sering ditemui sampah yang ada di toilet maupun disekitar obyek wisata pantai, untuk mengatasi masalah tersebut diperlukan strategi yang tepat dan efisien dengan menambah unit tempat sampah dan meletakkannya di tempat-tempat yang strategis. Selain itu perlu adanya kesadaran dari masyarakat untuk mengelola kebersihan. Selain itu menambah papan pengumuna dan spanduk. Hal ini sejalan dengan pendapat Maharani $d k k$, (2015) bahwa peningkatan kebersihan melalui pengadaan tempat sampah pada spotspot tertentu sangat penting dilakukan mengingat biota-biota ekosistem pantai sangat rentan terhadap pencemaran sampah.

Tata letak fasilitas dan sarana tetap memperhatikan aspek estetika kawasan. Pengunjung tidak hanya tertarik pada objek daya tarik Pantai Batu Gong dan fasilitas yang tersedia saja, penataan fasilitas seperti penataan gazebo juga tidak luput dari perhatian, dengan memberi nomor pada setiap gazebo akan memudahkan pengunjung maupun pengelola dalam menandai nomor gazebo yang tersedia. Hal ini sejalan dengan pendapat Saparinto (2007) bahwa kawasan ekowisata dikatakan optimal apabila lokasi dan jenis kegiatan telah dapat ditentukan, keteraturan dan keserasian sarana dan prasarana disesuaikan dengan kondisi objek, kenyamanan dan keamanan pengunjung terjamin.

- Meningkatkan Kegiatan Promosi di Media Sosial dan Media Cetak untuk Memperkenalkan Objek Wisata

Berdasarkan hasil perengkingan prioritas utama yang digunakan untuk strategi pengembangan wisata Pantai Batu Gongyakni meningkatkan kegiatan promosi di media sosial dan media cetak untuk memperkenalkan objek wisata yang dinyatakan sebagai prioritas ke-7. Walaupun Pantai Batu Gong telah lama didirikan kegiatan promosi juga perlu diperhatikan, karena tinggi dan rendahnya jumlah kunjungan wisatawan salah-satunya dipengarugi oleh kurangnya promosi Pemanfaatan media sosial seperti facebook, instagram dan twitter serta media cetak seperti brosur 
perlu ditingkatkan sehingga dapat menjadi solusi yang tepat untuk memperkenalkan Pantai Batu Gong kepada masyarakat. Hal ini sejalan dengan pendapat Nafiah (2010) dan Nugroho et al., (2013) bahwa promosi obyek pariwisata kepada masyarakat digunakan mengetahui bahwa ada obyek pariwisata yang baik untuk di kunjungi serta dapat meningkatkan jumlah arus kunjungan wisatawan.

\section{d. Strategi W-T}

- Meningkatkan Kebersihan Pantai dan Pengontrolan dari Pihak Berwajib Untuk Mengurangi Resiko Tawuran/P erkelahian dan Tindak Kriminal

Berdasarkan hasil perengkingan prioritas utama yang digunakan untuk strategi pengembangan wisata Pantai Batu Gongyakni Meningkatkan kebersihan pantai dan pengontrolan dari pihak berwajib untuk mengurangi resiko tawuran/perkelahian dan tindak kriminal yang dinyatakan sebagai prioritas ke-4. Pengamanan kawasan wisata sangat penting dilakukan mengingat kawasan wisata khususnya pantai, yang perlu dilakukan adalah membuat posko-posko keamaan dan menyedikan life guard, sehingga dapat memperhatikan pengunjung yang berada pada kawasan yang rawan. Pengamanan lainnya adalah pemasangan rambu-rambu/larangan tempat berbahaya untuk tempat mandi para pengunjung. Antisipasi ini harus segera dilakukan, mengingat kecelakaan sering terjadi pada waktu tahun baru/liburan sekolah dengan pengunjung yang sangat banyak terutama dari luar kota. Hal ini dapat diartikan bahwa kemanan merupakan hal yang penting untuk mengurangi resiko terjadinya tindak kriminal dan ancaman lainnya. Hal ini sesuai dengan pendapat Pratama dan Sakti, (2016) pihak yang berwajib atau keamanan sangat dibutuhkan sehingga dapat menciptakan rasa aman dan nyaman bagi wisatawan yang berkunjung di suatu obyek wisata.

\section{SIMPULAN}

Berdasarkan hasil yang telah diperoleh maka dapat disimpulkan bahwa strategi yang perlu diterapkan dalam pengembangan wisata pantai batu gongyakni(S-O) memanfaatkan lokasi mudah diakses wisatawan serta menambah fasilitas untuk menarik minat masyarakat untuk berkunjung, memanfaatkan lokasi yang membentang luas yang dapat digunakan sebagai lapangan pekerjaan sehingga dapat meningkatkan perekonomian masyarakat setempat, memanfaatkan teknologi media sosial dan media cetak untuk memperkenalkan objek wisata, dan memanfaatkan hubungan baik dengan seluruh stakeholderuntuk meningkatkan penyediaan fasilitas. (S-T) meningkatkan keamanan untuk menghindari terjadinya tindak kriminal pada wisatawan dan emanfaatkan lokasi yang mudah dijangkau, fasilitas yang tersedia sebagai keunggulan objek wisata dari pesaing objek wisata lain. (W-O) meningkatkan hubungan melalui kerja sama yang baik dengan stackholder terkait pengelolaan kebersihan pantai, penataan serta persediaan gazebo dan meningkatkan kegiatan promosi di media sosial dan media cetak untuk memperkenalkan objek wisata. (W-T) meningkatkan kebersihan pantai dan pengontrolan dari pihak berwajib untuk mengurangi resiko tawuran/perkelahian dan tindak kriminal.

\section{UCAPAN TERIMAKASIH}

Ucapan terimakasih kepada kedua orang tua Bapak Thayeb dan Ibu Rahmah, Isteri ku tercinta Fitriyanti, S.Pi, 
Keluarga dan Teman-teman yang tidak ada hentinya memberikan support dan pengalaman yang berharga selama ini.

\section{DAFTAR PUSTAKA}

Ayob, M., Z, Saman, F., M, Hussin Z, Jusoff, K. 2009. Tourist's Satisfaction on Kilim River Mangrove Forest Ecotourism Service. Intl J Manag, 4 (7): 7648.

Pratama, H., F \& Sakti, B. 2016. Strategi Pengembangan Kawasan Wisata Pantai Panjang Bengkulu, Ditinjau dari Perspektif Wisatawan dan Masyarakat Lokal. Ekombis Review: Jurnal Ilmiah Ekonomi dan Bisnis, 4 (2): 169-176.

Hepi, Meriatul, I., Yusri A, Luchman H. 2015. Analisis Pengembangan Wisata Pantai Indah Popoh Sebagai Daerah Tujuan Wisata Kabupaten Tulungagung. Jurnal Administrasi Bisnis, 26 (2): 2329.

Maharani, W., P, Arief, H, Sunarminto, T. 2015. Pengembangan
Ekowisata Mangrove di Pantai Bilik dan Sejile Resort Labuhan Merak Taman Nasional Baluran Jawa Timur. Jurnal Bonorowo Wetlands, 6 (2): 92-102.

Nafiah, M. 2010. Peranan Obyek Pariwisata Pantai Cermin Dalam Pengembangan Ekonomi Lokal. Skripsi. Universitas Sumatera Utara. Medan.

Razak, F., Olfie, B., Kapantow, G. 2017. Strategi Pengembangan Wisata Bahari Pantai Malalayang Kota Manado Sulawesi Utara. Jurnal Agri-Sosio Ekonomi Unsrat. 13 (1): 277-284.

Nugroho, P., Yusuf, M., Suryono. 2013. Strategi Pengembangan Ekowisata di Pantai Pangandaran Kabupaten Ciamis Pasca Tsunami. Jurnal of Marine Research.2 (2): 11-21.

Rencana Pembangunan Jangka Menengah Daerah (RPJMD) Kabupaten Konawe Tahun 2008 2013. Konawe Selatan

Saparinto, C. 2007. Pendayagunaan Ekosistem Mangrove. Dahara Prize. Semarang. 